Differential Geometry

By Prof. Erwin Kreyszig. (Mathematical Expositions, No. 11.) Pp. xiv +352. (Toronto : University of Toronto Press; London: Oxford University Press, 1959.) 48s, net.

$\prod_{\text {relotivi }}$ HE calm backwater of classical differential geometry was stirred up by the general theory of relativity and is now once more in the main stream : Prof. Kreyszig keeps within familiar euclidean space, but has in mind extensions to Riemannian geometry. $\mathrm{He}$ first deals with the curvature and torsion of a curve, defined rather artificially as normalizing factors for certain vectors associated with the curve, but quickly related to the more concrete notion of the components of the angular velocity of the fundamental orthogonal triad. Then he discusses the first and second ground forms for a surface and geodesic curvature, using tensor methods which are introduced and elaborated as they are needed. This part of the book gives the minimum which every mathematician must know, and Prof. Kreyszig has taken pains to make the argument both detailed and rigorous. For the rest of the book he selects certain more advanced topics of importance. There is a very good chapter on mapping, in which the unifying power of this concept is illustrated. Another chapter deals with Levi-Cività's parallel displacement as an introduction to the general theory. The final chapter covers a variety of special topies, such as minimal surfaces and surfaces of constant Gaussian curvature. Exercises for the student are interesting and not oppressively numerous. The teacher should find this book helpful because of the care with which topics have been chosen from a very wide field, and because of the skill with which analytical rigour and geometrical intuition have been mated.

Britain's National Parks

Edited by Harold M. Abrahams. Pp. $151+40$ photographs. (London: Country Life, Ltd., 1959.) 25s. net.

WHEN the first British national park was designated ten years ago it was hoped, in Lord Birkett's words, that "the fairest places in these islands will be secure from all assault arising from accident or design". With ten parks created this has proved to be far from the truth, and those who administer the parks need all the support they can get to resist the encroacher, both private and public.

This beautiful book, made up of a series of articles by men and women who know their parks lovingly and intimately, supported by photographs of the quality one expects from the publisher, should encourage all readers to join the ranks of those who see to it that encroachments are not made without due cause.

British Industries and Their Organization

By Prof. G. C. Allen. Fourth edition. Pp. $x i+332$. (London: Longmans, Green and Co., Ltd., 1959.) 25s. net.

TN this edition Prof. Allen has largely re-written his 1 book, which was first published in 1933 and substantially revised in 1951. The first chapter, which is substantially unaltered, traces the chief features of British industrial growth up to 1914 , and the second chapter, much enlarged, outlines the economic history of the period from 1914 to 1959 , so far as is relevant to the main theme of the book. The remaining ten chapters are concerned with particular industries; but, as in previous editions, the chemical and electrical industries are not included, and the book suffers a little in consequence. The select bibliography has also been completely revised.

\section{R. BrightMMAN}

Biographical Memoirs of the National Academy of Sciences of the United States of America

Vol. 33. Pp. vi $+484+16$ plates. (New York: Columbia University Press; London : Oxford University Press, 1959.) 40s. net.

THE "Biographical Memoirs" of the U.S. National Academy of Seiences are the counterpart of the Obituary Notices of the Royal Society, and Vol. 33 worthily maintains the high standard. The memoirs it contains are noteworthy for the completeness of the bibliographies appended to each memoir, but the time-span is exceptional, ranging from Josiah Boyce (September 14, 1916) and M. C. Wood, jun. (January 3,1920 ) to P. D. Merica (October 20, 1957), though apart from Dunham Jackson. (1946) and T. H. Morgan (1945) the subjects of the remaining memoirs died between 1950 and 1957. Among the memoirs likely to be of the widest interest to British readers are those of Isaiah Bruman, R. A. Millikan and L. F. Small.

The Wealth of India

A Dictionary of Indian Raw Materials and Industrial Products. Raw Materials, Vol. 5: H-K. Pp. $\mathrm{xxv}+332+\mathrm{xii}+16$ plates. (Now Delhi : Council of Scientific and Industrial Research, 1959.) Rs. 30.

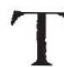

HE appearance of the fifth volume of this work will be welcomed, the first volume having appeared twelve years ago. According to the chief editor's introduction it is considered that half the total work has now been printed. With the machinery for the preparation of this gigantic task now apparently well organized and tried, it may be that the remaining five volumes will be completed in a shorter time. It would seem that the task may well take twenty years to complete. This is not unduly long, however, when one considers how long other similar large tasks, involving several authors, take to complete. For example, some of the large tropical floras now in preparation are unlikely to be completed in less than twenty or even thirty years.

This volume follows a similar pattern to the previous four volumes and contains a great deal of useful information presented in a form readily intelligible to the ordinary reader. It is well illustrated with line drawings, photographs and a few coloured plates. The coloured frontispiece is the sunflower (Helianthus annuus), which is, of course, of American origin. A typically Indian economic plant would perhaps have been more appropriate.

The volume deals with the raw materials falling under the letters $\mathrm{H}-\mathrm{K}$. It contains 380 entries- -370 on plants, 7 on animals and 3 on minerals. The preponderance of plant raw materials, compared with animal and mineral, is no cause for surprise to those familiar with the amazing richness in economic plants which Nature has so generously bestowed upon the Indian sub-continent. Important products in this volume include-Hevea (rubber), Hibiscus (with several different economic plants), Hordeum (barley), Hydnocarpus (chaulmoogra oil), Indigofera (dyes), Ipomoea (sweet potato), jade, Jasminum (perfumes) and Juglans (wainut).
F. N. Howes 